\title{
NMDA Antagonists as Neurotherapeutic Drugs, Psychotogens, Neurotoxins, and Research Tools for Studying Schizophrenia
}

John W. Olney, M.D., and Nuri B. Farber, M.D.

Antagonists of the N-methyl-D-aspartate (NMDA) subtype of glutamate (Glu) receptor have become the focus of considerable attention as potential neurotherapeutic agents in view of mounting evidence implicating NMDA receptors in acute central nervous system (CNS) injury syndromes such as stroke, trauma, and status epilepticus. In addition, NMDA receptor antagonists are of potential interest for the clinical management of neuropathic pain and preventing the development of tolerance to opiate analgesics. A potentially serious obstacle to the development of NMDA antagonists as neurotherapeutic drugs is the paradoxical fact that whereas these agents do have significant neurotherapeutic potential, they also have psychotogenic and neurotoxic properties. We have been intensively investigating the mechanisms underlying these adverse properties and have discovered several methods of

KEYWORDS: NMDA antagonist neurotoxicity; Posterior cingulate and retrosplenial cortices; Emergence reactions; Psychosis; Schizophrenia; Pain; Addiction

\section{NMDA RECEPTOR HYPOFUNCTION (NRH): A TOOL FOR STUDYING SCHIZOPHRENIA}

NMDA receptor hypofunction (NRH) is the condition induced in the brain of an experimental animal or hu-

From the Department of Psychiatry, Washington L niversity School of Medicine, St. Louis, Missouri.

Address correspondence to: John W. Olney, M.D., Department of Psychiatry, Washington University School of Medicine, 4940 Children's Place, St. Louis, MO 63110

Received December 9, 1994; revised April 4. 1995; accepted Mav 3, 1995 suppressing or preventing their expression. In addition, we have been exploring the possibility that a common mechanism may underlie the psychotogenic and neurotoxic actions of these agents and that this mechanism may have relevance to the pathogenesis of idiopathic psychotic processes such as schizophrenia. In this chapter, we will review our findings pertaining to NMDA antagonists in the dual context of their value as tools for exploring mechanisms underlying neuropsychiatric disturbances, particularly schizophrenia, and their potential promise as therapeutic agents. For additional references and a more complete elaboration of our hypothesis pertaining to NMDA receptor dysfunction and schizophrenia, please see a recent review (Olney and Farber 1995). INeuropsychopharmacology 13:335-345, 1995]

man subject treated with an NMDA antagonist. NRH may also be viewed as a transmitter disturbance that might be induced in the human brain by a disease mechanism and could be responsible for signs and symptoms of the disease process. If administration of NMDA antagonists to animals or people reproduces signs or symptoms of a disease process, this makes these drugs useful research tools for studying the potential role of $\mathrm{NRH}$ in that disease process. Based on this principle, we have been using NMDA antagonists as tools for studying schizophrenia. Schizophrenia is an idiopathic illness characterized by: (1) onset in early adulthood of a psychotic disturbance consisting of symptoms broadly divided into positive, negative, and disorganized categories; (2) structural brain changes that some investigators believe originate in early life and others believe may originate in adulthood; (3) cogni- 


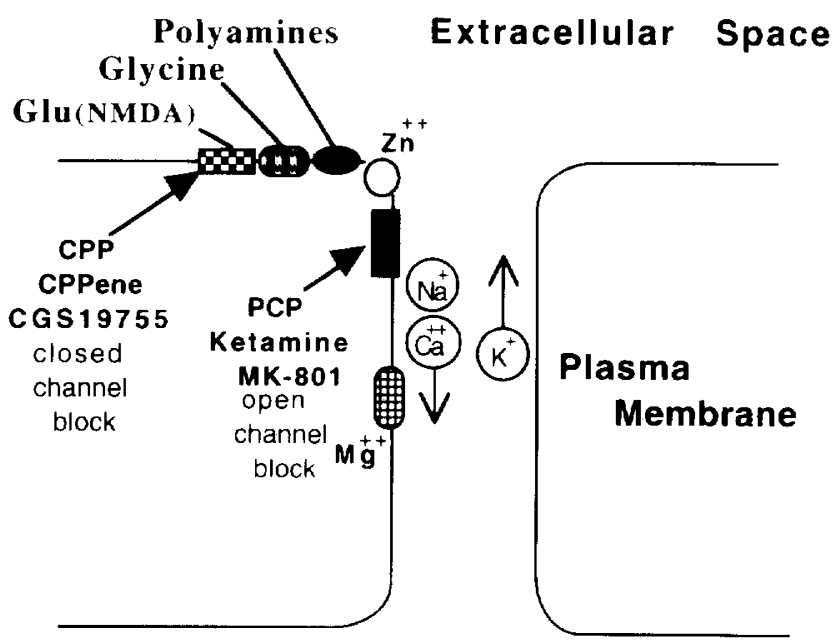

\section{Cytosol}

Figure 1. NMDA receptor channel complex. Associated with this complex are multiple recognition sites through which receptor channel function is modulated. Currently it is recognized that NMDA receptor hypofunction (NRH) results in psychosis in humans and cerebrocortical damage in rats regardless of whether the NRH is induced by agents (PCP, ketamine, MK-801) acting at the PCP site to perform an open channel block or agents (CPP, CPPene, CGS 19755) acting at the NMDA site to perform a closed channel block.

tive deterioration in some patients. In this article we will advance the proposal that NRH is a condition that, if present in the brain of a schizophrenic, could explain much of the symptomatology and natural course of this baffling disorder.

\section{NRH Is Psychotogenic}

The remarkable discovery by Lodge and colleagues $(1982,1987)$ that phencyclidine (PCP), a well-known psychotomimetic drug, noncompetitively blocks the ion channel of the NMDA subtype of Glu receptor (Figure 1) prompted several authors to postulate a role for NMDA receptors in schizophrenia. The hypothesis as initially formulated (Olney 1988) held that because blockade of NMDA receptor function by PCP is associated with schizophrenia-like psychotic symptoms, NMDA receptor hypofunction (NRH) per se may be psychotogenic and may be viewed as a candidate mechanism to explain schizophrenia. There now is new evidence confirming that NHR per se is psychotogenic. Three competitive NMDA antagonists (CPP, CPP-ene, CGS 19755) that block NMDA receptors by acting at the NMDA (rather than $\mathrm{PCP}$ ) recognition site (Figure 1) have now been administered to human subjects, and each was found in low dosage to induce a PCP-like psychotic reaction (Kristensen et al. 1992; Grotta 1994; Herr- ling 1994). Therefore, the phenomenon known for decades as PCP psychosis is not a PCP receptor-specific phenomenon, but rather is a phenomenon resulting from effective blockade of the NMDA receptorionophore complex-effective induction of $\mathrm{NRH}$.

\section{The Schizophrenomimetic Quality of NRH-Induced Psychosis}

Three decades ago PCP was introduced into clinical medicine as an anesthetic, but was soon withdrawn because it caused a high incidence of psychotic "emergence" reactions. The mental effects of PCP included not only hallucinations and delusions but also blunting of affect, apathy, catatonia, and thought disorder. Researchers in this era also noted that PCP could trigger a prolonged recrudescence of the acute psychotic state in chronic stable schizophrenics. Over the past 30 years illicit use of PCP has resulted in countless individuals being admitted to psychiatric hospitals with a psychotic illness difficult to distinguish from schizophrenia in acute, subacute, or (sometimes) chronic manifestations. Soon after PCP was withdrawn from clinical use it was replaced by ketamine, a dissociative anesthetic that has subsequently been identified as a $P C P$ receptor ligand and, like $P C P$, a noncompetitive blocker of the NMDA receptor ion channel. Although ketamine induces PCP-like emergence reactions, anesthesiologists have learned that these reactions can be suppressed by benzodiazepines or prevented by barbiturates. The psychotic reactions induced by PCP and ketamine are very similar, and most authors agree that these drugs, more faithfully than other psychotomimetics, mimic the full spectrum of signs seen in schizophrenia.

\section{NRH Can Produce Brain Damage}

In recent years it has been shown that various NMDA antagonists, both competitive and noncompetitive, that cause psychotic reactions in humans cause neurodegenerative changes in corticolimbic regions of rat brain (Olney et al. 1989b, 1991; Hargreaves et al. 1993a). After a low subcutaneous dose $(0.2$ to $0.5 \mathrm{mg} / \mathrm{kg} \mathrm{MK}$ 801 ), the neuronal injury consists of a vacuole reaction that is reversible and is restricted to neurons of the posterior cingulate and retrosplenial (PC/RS) cortex, but higher doses can cause a neuron-necrotizing reaction that spreads beyond the PC/RS cortex to involve neurons in several additional neocortical and limbic brain regions (Fix et al. 1993; Wozniak et al. 1993; Corso et al. 1994; Sharp et al. 1994). In addition, it has been reported that repeated injections of PCP or MK- 801 over a 3- to 4-day period induces a pattern of neurodegenerative changes distributed over several corticolimbic 
brain regions (Corso et al. 1992; Horvath and Buzsaki 1993; Ellison and Switzer 1993; Ellison 1994). These findings signify that persistent suppression of NMDA receptor function - that is, persistent $\mathrm{NRH}$ - for only a few days can result in relatively subtle but permanent structural changes. The distribution of neuronal degeneration induced by $\mathrm{NRH}$ in the adult rat brain is roughly similar to the distribution of abnormalities reported in the schizophrenic brain (see Bogerts 1993 for review), which includes the cingulate cortex (Benes et al. 1986), hippocampus (Kovelman and Scheibel 1984; Bogerts et al. 1985, 1986; Falkai and Bogerts 1986; Jeste and Lohr 1989; Shenton et al. 1992), parahippocampal gyrus (Brown et al. 1986; Shenton et al. 1992), and entorhinal cortex (Jakob and Beckman 1986; Falkai et al. 1988).

\section{NRH-Induced Brain Damage: Mechanisms and Prevention}

Over the past several years we have intensively studied underlying mechanisms and methods of preventing NRH-induced brain damage. The basic strategy used in most experiments was as follows: MK- 801 was administered systemically to adult female rats in a dose $(0.5 \mathrm{mg} / \mathrm{kg} \mathrm{SC})$ sufficient to induce a fully developed acute vacuole reaction in PC/RS neurons, and simultaneously a neuroactive drug with specificity for a given transmitter system was injected intraperitoneally or directly into certain brain regions in an attempt to block the neurotoxic reaction. In some experiments we injected various agents directly into the PC/RS cortex in an effort to reproduce the vacuole reaction by activation of specifically identified proximal mechanisms. Four hours after pharmacologic treatment(s), the animals were killed and the brains evaluated quantitatively for the number of vacuolated neurons in the PC/RS cortex.

From experiments, including those in which all agents were administered systemically, we found (Olney et al. 1991, 1993; Olney and Farber 1994; Farber et al. 1993a, b, 1995a, b; Farber and Olney unpublished observations) that several classes of drugs effectively block the PC/RS neurotoxic action of MK-801, including: (1) muscarinic receptor antagonists; (2) $\mathrm{GABA}_{A}$ facilitators (benzodiazepines and barbiturates); (3) sigma receptor ligands; (4) nonNMDA glutamate receptor antagonists; (5) $\alpha_{2}$-adrenergic receptor agonists; (6) certain typical antipsychotic agents (haloperidol, thioridazine, loxapine); (7) atypical antipsychotic agents (clozapine, fluperlapine, olanzapine).

From additional experiments, including those in which agents were administered intracranially, we found (Price et al. 1994; Olney and Farber 1995; Farber and Olney unpublished observations) that the circuit mediating the $\mathrm{PC} / \mathrm{RS}$ neurotoxic reaction involves neurons not only in the PC/RS cortex, but in the thalamus, basal forebrain, and brainstem. We also found that several transmitter pathways must be activated simultaneously for the PC/RS reaction to occur. This was confirmed by injecting a muscarinic agonist (carbachol), a sigma agonist $([+$ SSF 10,047) and a nonNMDA glutamate agonist (kainic acid) into the PC/RS region either as single drug injections or as a combination cocktail. We found that injection of only one or any two of these agents did not reproduce the vacuole reaction, but injection of all three faithfully did reproduce the full reaction. This suggests that the proximal mechanism responsible for this neurotoxic reaction is simultaneous hyperactivation of three receptors (muscarinic, sigma, kainate) on the PC/RS neuron.

\section{Proposed Circuitry to Explain NRH-Induced Brain Damage}

In Figure 2 we present a circuit diagram consistent with our several findings that can explain NRH-induced neurodegeneration in terms of a complex disinhibition principle. We propose that glutamate acting through NMDA receptors on GABAergic neurons maintains tonic inhibition over three separate excitatory pathways that convergently innervate the PC/RS neuron.

We propose that the first excitatory pathway originates locally in the PC/RS cortex and releases an endogenous agent that serves as a facilitative modulator of a sigma receptor on the PC/RS neuron. Tentatively we propose that the endogenous substance may be neuropeptide Y (NPY) in that several recent studies have identified NPY as a facilitative modulator of sigma receptors.

The second excitatory pathway is cholinergic and originates in the diagonal band region of the basal forebrain. It is known that diagonal band neurons project to the PC/RS cortex and account for $75 \%$ of the cholinergic innervation of $P C / R S$ cortex.

The third excitatory pathway is glutamatergic and originates in the anterior thalamus, which is known to send projections to PC/RS cortex.

We also propose that the network includes a fourth pathway that involves a noradrenergic neuron. Our basis for proposing involvement of noradrenergic neurons is that $\boldsymbol{\alpha}_{2}$-adrenergic receptor agonists block MK801 neurotoxicity (Farber et al. 1995a). We propose that normally the noradrenergic neuron is driven by glutamate through an NMDA receptor which results in release of norepinephrine at an $\alpha_{2}$-receptor on cholinergic neurons in the basal forebrain that project to PC/RS cortex. Thus, the basal forebrain cholinergic neurons are subject to two tonic inhibitory inputs, both of which are driven by glutamate through NMDA receptors and, 


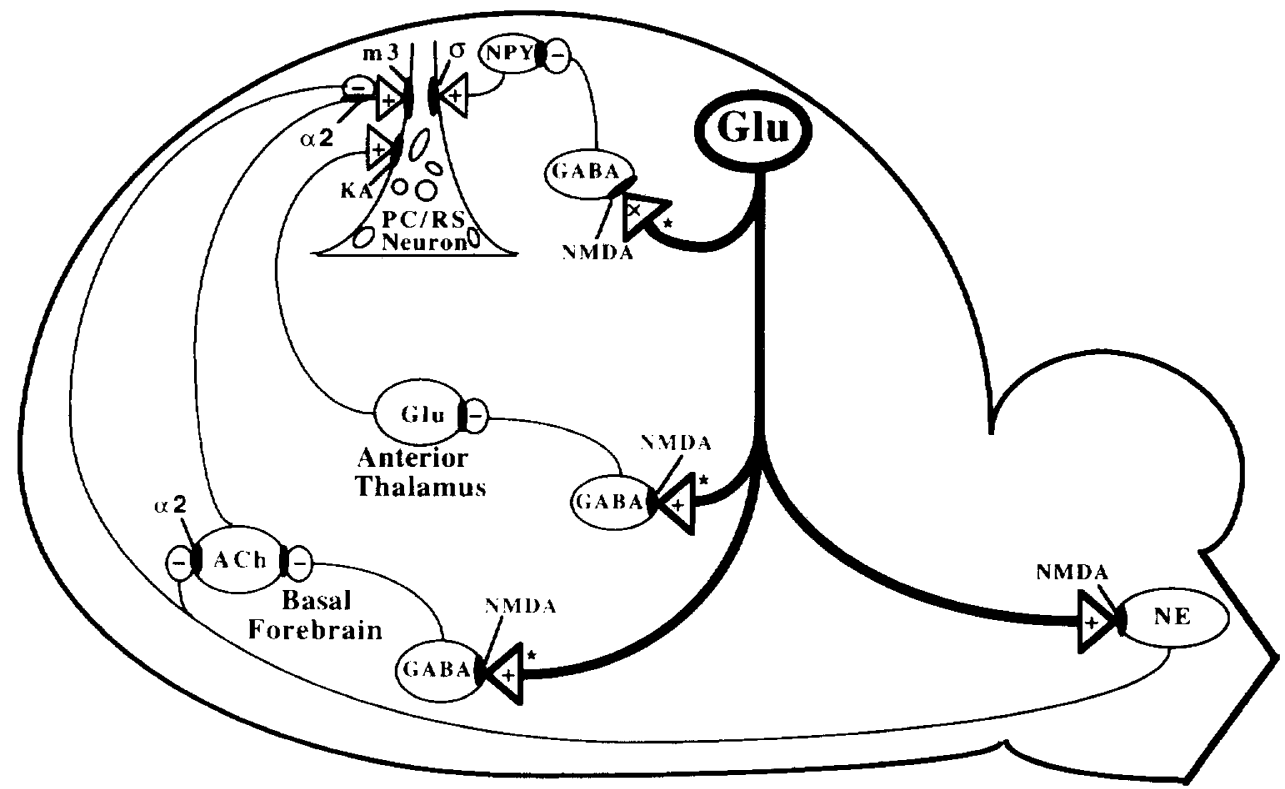

Figure 2. Postulated circuitry to explain the neurotoxic action of NMDA antagonists on PC/RS neurons. Glu acting at NMDA receptors on GABAergic neurons maintains tonic inhibition over three excitatory inputs to PC/RS neurons. Blocking NMDA receptors abolishes this inhibitory control mechanism, thereby causing all three excitatory inputs to excessively stimulate the PC/RS neuron. In addition, we postulate that Glu also maintains tonic inhibition over one of these excitatory systems (the ACh system) by driving NMDA receptors on norepinephrine (NE) neurons in the brainstem. The NE neurons project to the forebrain and terminate at $\alpha_{2}$-adrenergic receptors either on the cell bodies of cholinergic neurons in the basal forebrain or on their axon terminals in the PC/RS cortex. The asterisks indicate the postulated sites where dopamine inputs may presynaptically regulate Glu release. In this diagram we are suggesting that an excitatory input originates locally in the PC/RS cortex and releases an endogenous agent that serves as facilitative modulator of a sigma ( $\sigma$ ) receptor on the PC/RS neuron. Tentatively we propose that the endogenous substance may be neuropeptide $Y(N P Y)$ in that several recent studies have identified NPY as a facilitative modulator of sigma receptors (Monnet et al. 1990, 1992; Gue et al. 1992; Riviere et al. 1990). An additional possibility (not illustrated) would be that the PC/RS neuron uses Glu as a transmitter and gives off a recurrent collateral axon which, through an NMDA receptor on a local GABAergic neuron, exerts inhibitory control over its own firing rate. In this case, the NMDA antagonist would abolish inhibition in the recurrent collateral circuit, thereby removing inhibitory restraint over firing of the PC/RS neuron (at the same time that it is being hyperstimulated by multiple disinhibited excitatory inputs)

therefore, both are subject to disinhibition when NMDA receptors are blocked.

If we are correct that the PCIRS cortex receives convergent excitatory inputs from multiple subsystems, each of which is held under tonic inhibition by Glu acting at an NMDA receptor, systemic administration of an NMDA antagonist would simultaneously abolish inhibitory control over the excitatory limb of each subsystem, thereby causing the PC/RS neuron to be hyperstimulated through several signal transduction pathways at the same time. This would create chaotic disruption among intracellular second messenger systems and could lead to severe derangement of psychologic functions subserved by the neural network containing these afflicted neurons.

\section{Age Dependency of NRH-Induced Phenomena}

Farber et al. (1992; 1995c) have shown that fetal rats and postnatal rats less than 1.5 months of age (roughly puberty in the rat) are totally insensitive to MK-801induced cerebrocortical neurotoxicity. Between puberty (1.5 months) and full adulthood (3 to 4 months), they gradually become fully sensitive to this toxic mechanism and remain so for up to at least 10 months of age. Similarly anesthesiologists have learned that the incidence of emergence reactions associated with ketamine anesthesia is age-dependent, with the reaction occurring rarely, if ever, in prepubertal children but manifesting in nearly $50 \%$ of young to middle-aged adults (Marshall and Longnecker 1990). Thus, although NMDA 
antagonists undoubtedly induce NRH (that is, block NMDA receptors) in both immature rats and immature humans, this does not cause either morphologic neurotoxic effects or psychotomimetic effects during prepubertal periods of development.

\section{Latent NRH as a Developmental Mechanism in Schizophrenia}

It logically follows from the previously mentioned agedependency information that a lesion having NRH potential could be present in the developing human brain at birth and this would not trigger psychopathologic or neuropathologic processes until late adolescence, at which time it presumably would spontaneously begin to trigger schizophrenia-like psychotic symptoms. An in utero structural lesion having latent $\mathrm{NRH}$ psychotogenic potential that remains quiescent until late adolescence, would be quite consistent with current speculation that in utero structural brain changes occur in schizophrenia, and with the fact that psychotic symptoms potentially attributable to such structural changes do not begin to manifest until late adolescence.

The pathogenic potential of NRH is based on a disinhibitory principle. If NMDA receptors in certain circuits are hypofunctional, GABAergic inhibition over excitatory inputs to corticolimbic neurons is abolished. We postulate that these circuits normally mature and form their adult connections in late adolescence. At this time, if either the NMDA receptors or the GABAergic neurons possessing these receptors are missing or are impaired (due to an earlier developmental lesion), the newly formed circuits would be dysfunctional (uninhibited) and would allow unmodulated stimulatory activity to flood corticolimbic brain regions, a process that could produce psychotic symptoms initially and ongoing structural changes eventually if the $\mathrm{NRH}$ condition remains severe and unremitting. Highly relevant to this point is the fact that Benes et al. (1991) have reported a specific defect in the cerebral cortex of schizophrenics consisting of a loss of GABAergic neurons.

Accumulating evidence suggests that structural changes in cerebrocortical and limbic brain regions are a characteristic of schizophrenia, but opinions vary concerning whether such changes occur during development or in adulthood. The NRH hypothesis holds that both may be the case in that it posits structural changes of two different types, one with latent NRH potential that would occur during development, and another that would occur during adulthood and would represent the delayed pathological expression of the NRH potential of the earlier structural change. This is a compound unifying hypothesis that avoids the either-or impasse and accommodates several lines of evidence and/or speculation from both the experimental animal and human clinical literature.

\section{NRH Hypothesis and the Dopamine Transmitter System}

Traditionally, the most widely held hypothesis to explain positive schizophrenic symptoms has been the dopamine (DA) hyperactivity hypothesis. The most compelling evidence for the DA hypothesis of schizophrenia is the fact that DA receptor antagonists are at least partially effective in ameliorating positive symptoms in many cases of schizophrenia. Any schizophrenia hypothesis that does not explain this observation is a weak hypothesis. It is possible to improve the explanatory power of either the DA or Glu hypothesis by incorporating the former into the latter. For example, because one action of DA receptors is to inhibit Glu release (Schwarcz et al. 1978; Rowlands and Roberts 1980; Kornhuber and Kornhuber 1986; Maura et al. $1988,1989,1990)$, a primary defect in the DA system (Figure 2) causing DA hyperactivity could result in excessive suppression of Glu release at NMDA receptors with consequent hypofunction of the NMDA receptor system (NRH) as the basis for schizophrenia symptoms. Amelioration of symptoms by DA receptor blockers could be explained in terms of the DA receptor blockade disinhibiting Glu release thereby correcting Glu hypofunction.

If the postulated defect in the DA system were congenital or genetic in origin and, therefore, were present from birth, it would not be expected to produce psychotic symptoms until early adulthood because secondary induction of NRH is the mechanism by which DA hyperactivity would produce symptoms and, as discussed earlier, NRH does not trigger psychotic symptoms until early adulthood.

To explain cases of schizophrenia that are not responsive to DA receptor blockers, we propose that this may represent an etiologically different form of the disease in which NRH is present as a primary pathogenic factor in the absence of a primary disturbance in the DA system. To explain evidence that clozapine blocks NMDA antagonist neurotoxicity and is particularly effective in treating schizophrenic patients who manifest negative symptoms and who are neuroleptic resistant, whereas typical neuroleptics are primarily effective in treating positive symptoms, we propose that more than one neural pathway and more than one type of DA receptor may be involved, but in all pathways NRH may be an operative mechanism (because PCP and ketamine, which induce NRH, mimic both negative and positive symptoms of schizophrenia). 


\section{Therapeutic Implications of Schizophrenia}

Schizophrenia is an idiopathic illness characterized by psychosis with onset in early adulthood, corticolimbic brain damage, and cognitive deterioration; $\mathrm{NRH}$ is a transmitter disturbance which, if present in the schizophrenic brain from birth, could explain lack of symptoms in childhood, onset of psychotic symptoms in early adulthood, and ongoing corticolimbic brain damage with associated cognitive deterioration. NRH would be expected to produce an authentic schizophrenia-type psychosis in that drugs that induce NRH in human adults reproduce both the positive and negative symptoms of schizophrenia and are particularly effective in triggering a prolonged recrudescence of the acute psychotic state in stable chronic schizophrenic patients. Also consistent with the hypothesis that an NRH mechanism may be operative in schizophrenia is our finding that certain drugs, including haloperidol, clozapine, and thioridazine, which ameliorate symptoms of schizophrenia also prevent NRH from inducing structural damage in rat brain. If it can be shown that NRH is a mechanism operative in all or even some cases of schizophrenia, the pharmacotherapeutic implications are not trivial. A potentially important implication is that if the degree of NRH is severe, early pharmacologic intervention and continuous maintenance therapy may be necessary to prevent cognitive deterioration, because permanent brain damage is a potential consequence of persistent NRH. Therefore, a high priority question is whether medications currently being used to treat schizophrenia would be expected to reduce the risk of NRH-induced neurodegeneration.

Theoretically, in cases of schizophrenia in which NHR occurs secondary to a primary DA hyperactivity defect, the answer to the previous question should be yes because in such cases any form of therapy that normalizes DA activity would tend to correct the NRH and prevent NRH-induced neurodegeneration. On the other hand, it is possible that NRH induces some schizophrenic symptoms through one neural network and other symptoms through another, and structural brain changes might be induced through one or the other, or even through a third and different network. Assuming that multiple networks do exist, and that both a dopaminergic and NRH mechanism are involved in each, it is possible that $\mathrm{D}_{2}$ receptors modulate only one network and other DA receptor subtypes modulate the other(s). If so, typical neuroleptics that act primarily at $\mathrm{D}_{2}$ receptors would be effective in preventing structural brain changes only if these changes are induced through the specific network modulated by $D_{2}$ receptors. In view of evidence suggesting that negative symptoms may correlate with structural brain changes and cognitive deterioration and the clinical observation that typical neuroleptics are relatively ineffective in treating negative symptoms, there is basis for concern that typical neuroleptic medications may not be very useful in reducing the risk of $\mathrm{NRH}$-induced neurodegeneration. Although certain typical neuroleptics (haloperidol and thioridazine) block NRH-linked neurodegeneration in the rat, this could be explained by their sigma or muscarinic blocking activity, which might not be very strong at doses used in human neuroleptic therapy. Thus, at doses used in humans, these drugs may act on a network relevant to positive symptoms but have very little influence on the network(s) relevant to negative symptoms and structural brain damage. Although evidence suggesting that early pharmacological intervention results in a more favorable long-term outcome in schizophrenia, it is difficult to sort out the role of typical neuroleptics versus antimuscarinic agents in this long-term outcome.

Clozapine is effective in preventing NRH-linked neurodegeneration in rats and in treating both negative and positive symptoms in schizophrenic patients, including those who are resistant to typical neuroleptics. This suggests that a clozapine-sensitive network might exist through which NRH can induce both negative symptoms and pathomorphologic brain changes and that another network may exist which is sensitive to both clozapine and typical neuroleptics through which NRH induces primarily positive symptoms, but may induce little or no brain damage. Further animal research aimed at clarifying the specific circuitry and receptor systems through which clozapine acts to prevent NRH-linked neurodegeneration may provide clues to the mechanism(s) by which clozapine ameliorates negative symptoms of schizophrenia, and it will be interesting in future clinical research to determine whether clozapine proves effective in preventing not only negative symptoms but structural brain changes and cognitive deterioration.

It would be predicted from the NRH model that Glu agonists might be effective in ameliorating the symptoms of schizophrenia. Clearly, if a specific defect in NMDA receptor-mediated neurotransmission were identified, therapy aimed at compensating for that specific defect would be indicated. Current efforts to treat schizophrenic patients with glycinergic agents are based on this principle (Deutsch et al., 1989; Javitt et al. 1994). Theoretically, Glu agonists might also be useful in cases where DA hyperactivity is the basic defect and NRH occurs secondarily due to excessive inhibition of Glu release at certain NMDA receptors. Introduction of a selective agonist that can act at these NMDA receptors would correct the Glu hypofunctional state even though the DA hyperactivity would not be corrected. However, other forms of therapy based on the NRH model should be considered first since these might be less treacherous than using an agonist of Glu receptors that might have excitotoxic side effects in some brain regions while correcting Glu tone in other regions. 
The NRH model would suggest that activation of $\mathrm{GABA}_{\mathrm{A}}$ receptors may be therapeutic. Whereas a positive response to benzodiazepine treatment has been reported in a few studies that utilized very high doses or that investigated the catatonic subtype of schizophrenia or negative aspects of the illness, most studies have shown little or no value of benzodiazepines over placebo in the treatment of schizophrenia. These results are perhaps consistent with our finding that diazepam provides only partial protection against $\mathrm{NRH}$-induced neurodegeneration (Olney et al. 1991), which in turn is consistent with knowledge that benzodiazepines do not by themselves open the GABA chloride ion channel. They act only to potentiate the action of GABA, and under NRH conditions GABAergic neurons are inactivated so that in the synaptic cleft there is very little GABA to potentiate. Certain barbiturates, those referred to as anesthetic barbiturates, directly open the GABA chloride ion channel and, therefore, would theoretically be more effective in schizophrenia. However, they would probably not be very useful because at doses required to open the chloride ion channel they are sedative-hypnotics.

According to the NRH model, antimuscarinic agents might be therapeutically beneficial in schizophrenia. Some students of schizophrenia have maintained that cholinergic dysfunction plays an important role in the disease (Tandon and Greden 1989; Tandon et al. 1991). Specifically, it has been proposed that negative symptoms are caused by excessive muscarinic activity based on evidence that antimuscarinic drugs relieve negative symptoms and increase sociability (Fayen et al. 1988; Tandon et al., 1988), and that schizophrenic patients have a strong tendency to abuse antimuscarinic drugs in a quest for self-relief from negative symptoms (Fisch 1987; Wells et al. 1989). If, as posited earlier, there is a pathway through which NRH induces both negative symptoms and structural brain changes, several classes of drugs that block NRH-linked neurodegeneration in the rat, including antimuscarinics, sigma antagonists and nonNMDA Glu antagonists, might be expected to block negative symptoms, structural brain changes, and cognitive deterioration in schizophrenia We are not aware of any appropriately designed studies aimed at determining whether any of these classes of drugs, if administered in appropriate dosage at the onset of schizophrenia and continuously thereafter, would prevent negative symptoms, structural brain changes, and cognitive deterioration. Antimuscarinics have been used extensively in schizophrenia, but not in the absence of neuroleptics. Therefore, it is reasonable to propose that the ability of early pharmacologic intervention to improve the long-term outcome in schizophrenia might be explained by the practice of including antimuscarinic agents in the treatment regimen. It is also reasonable to propose that the powerful antimuscarinic ac- tion of clozapine might contribute not only to its lack of extrapyramidal side-effects but to its efficacy in blocking negative symptoms, and if future research reveals that clozapine prevents not only negative symptoms but structural brain changes and cognitive deterioration, its antimuscarinic action would be a prime candidate to help explain these therapeutic benefits.

\section{IMPLICATIONS FOR THE DEVELOPING CENTRAL NERVOUS SYSTEM}

The observation that neither fetal nor infant rats are vulnerable to the mechanism by which NMDA antagonists injure cerebrocortical neurons and that immature humans do not seem to be vulnerable to the psychotogenic actions of the NMDA antagonists, ketamine and PCP, is potentially important for the following reasons. It suggests that fetuses of PCP-abusing mothers may be at less risk for neurotoxic or psychotogenic side-effects than are the drug-abusing mothers. Moreover, it also suggests that NMDA antagonists may be safer for use as neuroprotective drugs in pediatric than adult medicine. This is of particular interest in view of accumulating evidence that in the developing CNS there is a certain time interval during which the NMDA receptor, due to overexpression of a specific receptor subunit (Monyer et al. 1994), is hypersensitive to excitotoxic stimulation (McDonald et al. 1988; Ikonomidou et al. 1989a, 1989b). Because other subtypes of Glu receptor at the same time are relatively hyposensitive (Campochiaro and Coyle 1978; McDonald et al. 1991), the NMDA receptor may be primarily responsible for excitotoxic neuropathology during critical periods of development. Therefore, NMDA antagonists are of particular interest as neuroprotectants for the developing CNS. Supporting this view is evidence that NMDA antagonists are very effective in preventing damage to the infant rat brain induced by either hypoxia/ischemia (McDonald et al. 1987; Ikonomidou et al. 1989a, 1989b; Olney et al. 1989a) or head trauma (Ikonomidou et al. 1994). Of course, before NMDA antagonists can be declared entirely safe for the immature CNS, other possible side-effects, including frank teratogenicity (Walker and Seig 1973) or a more subtle interference in trophic functions of NMDA receptors (Pearce et al. 1987; Balazs et al. 1988) must also be considered, especially for indications requiring chronic treatment.

\section{IMPLICATIONS FOR ADULT THERAPEUTIC USES OF NMDA ANTAGONISTS}

Clearly, if the psychotogenicity of NMDA antagonists in humans and neurotoxicity of these agents in rats are age-dependent with onset of vulnerability in early 
adulthood, this poses a potential obstacle to their use as therapeutic drugs in adult medicine. However, as several classes of drugs prevent the neurotoxic effects of NMDA antagonists, administering such drugs together with NMDA antagonists is a potential solution to the dilemma. Alternatively, it may be possible to develop an agent that incorporates within the same molecule strong NMDA antagonist therapeutic activity together with action at other receptors that interrupts the extended circuitry through which NMDA antagonist side-effects are mediated. Based on information presently available, the prospects are as follows:

Combining NMDA antagonists with GABAergic agents warrants consideration as GABAergic agents are known to suppress the psychotic side effects of ketamine and they also suppress the neurotoxic action of various NMDA antagonists in rat brain. However, because benzodiazepines are addictive and confer only partial protection, they may not be the agents of choice. Barbiturates would be expected to provide more complete protection, which would recommend these agents for conditions such as stroke and head trauma. However, their strong sedating action and addiction potential might disqualify them for more chronic applications.

Various antipsychotic (neuroleptic) agents that protect the rat brain against NMDA antagonist neurotoxicity are of interest. Atypical neuroleptics (clozapine, fluperlapine, olanzapine) are more potent than typical neuroleptics (haloperidol, loxapine, thioridazine) in blocking NMDA antagonist neurotoxicity, and are more effective in ameliorating a broad range of symptoms in schizophrenia. Therefore, provided they are not disqualified because of their own side-effects, atypical neuroleptics would seem more promising than typical neuroleptics as adjunctive agents for reducing the adverse site effects of NMDA antagonists.

In our opinion, high priority should be given to an evaluation of antimuscarinic drugs for their ability to protect human subjects against the psychotogenic side effects of NMDA antagonists. Antimuscarinics have not been evaluated for efficacy in preventing the psychotic side effects of ketamine, but we would predict that they might be at least partially effective, and if this were shown to be the case in carefully controlled human trials, this would add strong support to the proposal that a similar mechanism and similar circuitry are involved in producing the neurotoxic side effects in rat brain and psychotic side-effects in humans. It might be considered a contradiction to propose that an antimuscarinic such as scopolamine might prevent a PCP psychosis as it is known that a high dose of scopolamine by itself can induce psychotic symptoms. However, we propose that a certain level of muscarinic tone in cerebrocortical circuits is required for normal mental function and if this tone is either increased or decreased to an abnormal degree it may be psychotogenic. In the case at hand, administration of an NMDA antagonist would cause abnormal release of muscarinic activity in the PC/RS and possibly other corticolimbic brain regions and this abnormal muscarinic hyperactivity would be corrected by co-administration of scopolamine. Provided the scopolamine dose were adjusted to just counteract the abnormal cholinergic activation syndrome, it should be therapeutic without psychotoxic liability. Based on this reasoning, we would recommend that in the setting of NMDA antagonist therapy for stroke, neuropathic pain, or opiate dependence, antimuscarinics be given in a carefully controlled manner to determine whether the psychotic side-effects can thereby be brought under control. If they can, it may be assumed that the potential of the NMDA antagonist to induce cerebrocortical neuronal injury is probably also being blocked, and a class of drugs (NMDA antagonists) that have considerable neurotherapeutic potential would be rescued from ignominy by a principle as simple as administering two classes of drugs together in a carefully controlled manner.

The observation that $\alpha_{2}$-adrenergic agonists block MK-801 neurotoxicity (Farber et al. 1995a) is of potential interest, especially in relation to the therapeutic management of neuropathic pain, because both $\alpha_{2-}$ adrenergic agonists (Puke et al. 1993; Zeigler et al. 1992) and NMDA antagonists (Backonja et al. 1994; Davar et al. 1991; Kristensen et al. 1992) reportedly have an ameliorating effect on neuropathic pain. It will be of considerable interest in future research to determine whether combined treatment with agents of these two classes can provide superior control over neuropathic pain while simultaneously eliminating or reducing the adverse side-effects of NMDA antagonists.

Concerning the prospects of developing NMDA antagonists free from side-effects, it has been reported that agents that block NMDA receptor function by acting at the glycine site or polyamine site provide neuroprotection against hypoxic/ischemic neuronal degeneration without causing neuronal injury in the rat PC/RS cortex (Duval et al. 1992; Hargreaves et al. 1993b). It will be important for other laboratories to confirm these preliminary observations with respect to both the neuroprotective and neurotoxic actions of these compounds. In the meantime, healthy skepticism is warranted as other classes of NMDA antagonists produce neurotoxic side-effects in direct proportion to their efficacy in blocking NMDA receptors. If these agents are free from side-effects, it suggests that either they do not effectively block the specific NMDA receptors responsible for these side-effects, or else they interact with other receptor systems (muscarinic, sigma, GABA, $\alpha_{2}$-adrenergic) through which these side-effects can be counteracted. 


\section{SUMMARY AND CONCLUSIONS}

NMDA antagonists pose a complex dilemma for the pharmaceutical industry, regulatory agencies, and neuromedical sciences. These agents are potentially valuable for neurotherapeutic application in a wide variety of neuropsychiatric disorders, including stroke, CNS trauma, epilepsy, neuropathic pain syndrome, opiate dependence, and possibly chronic neurodegenerative diseases such as amyotrophic lateral sclerosis, Alzheimer's disease, and AIDS dementia. However, they also harbor treacherous potential for producing harmful side-effects that include induction of a schizophrenialike psychosis in humans and cerebrocortical neuronal injury in rats at doses not far removed from the range required for therapeutic benefits. In this article, we have reviewed recent research efforts aimed at clarifying the mechanism underlying the neurotoxic and psychotogenic potential of NMDA antagonists, described several methods that may be useful for controlling or preventing these harmful side-effects, and emphasized yet an additional fascinating aspect of the NMDA antagonist story, namely that these agents may prove to be exceedingly valuable research tools for clarifying mechanisms underlying psychotic symptom formation and pathomorphologic brain changes in idiopathic psychotic illnesses such as schizophrenia

\section{ACKNOWLEDGMENTS}

This work was supported in part by an NIMH Research Scientist Award MH 33894 (JWO), DA 06454, DA 05072, DA 07261. AG 05681, a research award from the Scottish Rite Benevolent Foundation's Schizophrenia Research Program to NBF and an Established Investigator A ward to JWO from NARSAD

\section{REFERENCES}

Backonja M, Arndt G, Gombar KA, Check B, Zimmermann M (1994): Response of chronic neuropathic pain syndromes to ketamine: A preliminary study. Pain 56:51-57

Balazs R, Hack N, Jorgensen OS (1988): Stimulation of the $\mathrm{N}$-methyl-D-aspartate receptor has a trophic effect on differentiating cerebellar granule cells. Neurosci Lett $87: 80-86$

Benes FM, Davidson J, Bird ED (1986): Quantatative cytoarchitectural studies of the cerebral cortex of schizophrenics. Arch Gen Psychiatry 43:31 35

Benes FM, McSparren ], San-Giovanni IP, Vincent SL (1991) Deficits in small interneurons in cingulate cortex of schizophrenic and schizoaffective patients. Arch Gen Psychiatry 48:996-1001

Bogerts B, Meertz E, Schonfeldt-Bausch R (1985): Basal ganglia and limbic system pathology in schizophrenia: A morphometric study of brain volume and shrinkage. Arch Gen Psychiatry 42:784-791

Bogerts B, Falkai P, Tutsch J (1986): Cell numbers in the pallidum and hippocampus of schizophrenics. In Shagass $C$. Josiassen RC, Bridger WH, Weiss KJ, Stoff D, Simpson GM (eds), Biological Psychiatry, vol 7, Amsterdam, Elsevier, pp 1178-1180

Bogerts B (1993): Recent advances in the neuropathology of schizophrenia. Schisophrenia Bull 19:431-445

Brown R, Colter N, Corsellis JAN, Crow TJ, Frith CD, Jagoe R, Johnstone EC, Marsh L (1986): Post-mortem evidence for structural brain changes in schizophrenia. Differences in brain weight, temporal horn area and parahippoampal gyrus width as compared with affective disorder. Arch Gen Psychiatry 43:36-42

Campochiaro P, Coyle JT (1978): Ontogenetic development of kainate neurotoxicity: Correlates with glutamatergic innervation. Proc Natl Acad Sci 75:2025-2029

Corso T, Neafsey EL, Collins M (1992): Ethanol-induced degeneration of dentate gyrus, entorhinal cortex and other olfactor related areas in rat: Effects of co-administration of MK-801, DNQX, or nimodipine. Soc Neurosci Abstr 18:540

Corso TD, Wozniak DF, Sesma MA, Olney JW (1994): Neuron necrotizing properties of phencyclidine. Soc Neurosci Abstr 20:1531

Davar G, Hama A, Deykin A, Vos B, Maciewicz R (1991): MK801 blocks the development of thermal hyperalgesia in a rat model of experimental painful neuropathy. Brain Res 553:327-330

Deutsch SI, Mastropaolo J, Schwartz BL, Rosse RB, Morihisa JM (1989): A "glutamatergic hypothesis" of schizophrenia. Rationale for pharmacotherapy with glycine. Clin Neuropharmacol 12(1):1-13

Duval D, Roome N, Gauffeny C, Nowicki JP, Scatton B (1992): SL 82.0715, an NMDA antagonist acting at the polyamine site, does not induce neurotoxic effects on rat cortical neurons. Neurosci Lett 137:193-197

Ellison G, Switzer RC (1993): Dissimilar patterns of degeneration in brain following four different addictive stimulants. Neuroreport 5:17-20

Fllison G (1994): Competitive and non-competitive NMDA antagonists induce similar limbic degeneration. Neuroreport 5:2688-2692

Falkai P, Bogerts B (1986): Cell loss in the hippocampus of schizophrenics. Psychiatr Neurol Sci 236:154-161

Falkai P, Bogerts B, Rozumek M (1988): Limbic pathology in schizophrenia: The entorhinal region-A morphometric study. Biol Psychiatry 24:515-521

Farber NB, Price MT, Labruyere J, Fuller TA, Olney JW (1992): Age dependency of NMDA antagonist neurotoxicity. Soc Neurosci Abstr 18:1148

Farber NB, Price MT, Labruyere J, Nemnich J, St. Peter H, Wozniak DF, Olney JW (1993a): Antipsychotic drugs block phencyclidine receptor-mediated neurotoxicity. Biol Psychiatry 34:119-121

Farber NB, Price MT, Labruyere J, Nemnich J, St. Peter H, Olney JW (1993b): Protection against NMDA antagonist neurotoxicity by clozapine and related analogs correlates with antipsychotic efficacy. Soc Neurosci Abstr 19:384 
Farber NB, Foster J, Duhan NL, Olney JW (1995a): A2 adrenergic agonists prevent MK- 801 neurotoxicity. Neuropsychopharmacology 12(4):347-349

Farber NB, Foster J, Olney JW (1995b): Clozapine and related analogs block NMDA antagonist neurotoxicity: Implications for schizophrenia. Schizophr Res 15(1,2):57-58

Farber NB, Wozniak DF, Price MT, Labruyere J, Huss J, St. Peter H, Olney JW (1995c): Age-specific neurotoxicity in the rat associated with NMDA receptor blockade: Poten tial relevance to schizophrenia? Biol Psychiatry 37:(in press)

Fayen M, Goldman MB, Moulthrop MA, Luchins DJ (1988): Differential memory function with dopaminergic versus anticholinergic treatment of drug-induced extrapyramidal symptoms. Am J Psychiatry 145:483-486

Fisch RJ (1987): Trihexiphenidyl abuse: Therapeutic implications for negative symptoms of schizophrenia. Acta Psychiatr Scand 75:91-94

Fix AS, Horn JW, Wightman KA, Johnson CA, Long GC Storts RW, Farber NB, Wozniak DF, Olney JW (1993): Neuronal vacuolization and necrosis induced by the noncompetitibve N-methyl-D-aspartate (NMDA) antagonist MK(+)801 (Dizocilipine Maleate): A light and electron microscopic evaluation of the rat retrosplenial cortex. Exp Neurol 123:204-215

Grotta J (1994): Safety and tolerability of the glutamate antagonist CGS 19755 in acute stroke patients. Stroke 25:255

Gue M, Junien JL, Del Rion C and Bueno L (1992). Neuropeptide $Y$ and Sigma ligand (JO 1784) suppress stress-induced colonic motor distrubances in rats through sigma and cholecystokinin receptors. J Pharm Exp Ther 261:850-855

Hargreaves RJ, Rigby M, Smith D, Hill RG, Iversen LL (1993a): Competitive as well as uncompetitive NMDA receptor antagonists affect cortical neuronal morphology and cerebral glucose metabolism. Neurochem Res 19:1263-1269

Hargreaves RJ, Rigby M, Smith D, Hill RG (1993b): Lack of effect of L-687,414[(+)-cis-4-methyl-HA-966, an NMDA receptor antagonist acting at the glycine site, on cerebral glucose metabolism and cortical neuronal morphologv Br J Pharmacol 110:36-42

Herrling PL (1994): D-CPPene (SDZ EAA 494), A competitive NMDA antagonist: Results from animal models and frst results in humans. Neuropsychopharmacology 10:591S

Horvath Z, Buzsaki G (1993): MK-801-induced neuronal dam age in normal rats. Soc Neurosci Abstr 19:354

Ikonomidou C, Price MT, Mosinger JL, Frierdich G, Labruvert J, Shahid Salles K, Olney JW (1989a): Hypbaric-ischemx conditions produce glutamate-like cytopathology in in fant rat brain. J Neurosci 9: 1693-1700

Ikonomidou C, Mosinger JL, Shahid Salles K, Lubryere I Olney JW (1989b): Sensitivity of the developing rat brain to hypobaric/ischemic damage parallels sensitivity to $\mathrm{N}$-methyl-aspartate neurotoxicity. J Neurosci 9:2809-2818

Ikonomidou C, Qin YO, Labruyere J, Olney JW (1994): Trauma causes glutamatetype cytopathology in infant rat brain Soc Neurosci Abstr 20:1677

Jakob H, Beckman H (1986): Prenatal developmental distur bances in the limbic allocortex in schizophrenics. I Neu ral Transmiss 65:303-326
Javitt DC, Zylberman I, Zukin SR, Heresco-Levy U, Lindenmayer JP (1994): Amelioration of negative symptoms in schizophrenia by glycine. Am J Psychiatry 151:1234-1236

Jeste D, Lohr JB (1989): Hippocampal pathologic findings in schizophrenia. Arch Gen Psychiatry 46:1019-1024

Kornhuber J, Kornhuber ME (1986): Presynaptic dopaminergic modulation of cortical input to the striatum. Life Sci 39:699-674

Kovelman JA, Scheibel AB (1984): A neurohistological correlate of schizophrenia. Biol Psychiatry 191:1601-1621

Kristensen JD, Svensson B, Gordh T (1992): The NMDAreceptor antagonist $\mathrm{CPP}$ abolishes neurogenic "wind-up pain" after intrathecal administration in humans. Pain 51:249-253

Lodge D, Aram JA, Church J, Davies SN, Martin D, O'Shaughnessy CT, Zeman S (1987): Excitatory amino acids and phencyclidine-like drugs. In Hicks TP, Lodge D, McLennan H (eds), Excitatory Amino Acid Transmission. New York, Alan R. Liss, pp 83-90

Lodge D, Anis NA (1982): Effects of phencyclidine on excitatory amino acid activation of spinal interneurons in the cat. Eur J Pharmacol 77:203-204

McDonald JW, Silverstein FS, Johnston MV (1987): MK-801 protects the neonatal brain from hypoxic-ischemic damage. Eur J Pharmacol 140:359-361

McDonald JW, Silverstein FS, Johnston MV (1988): Neurotoxicity of N-methyl-D-aspartate is markedly enhanced in developing rat central nervous system. Brain Res 459: 200-203

McDonald JW, Trescher WH, Johnston MV (1991): The pattern and degree of selective vulnerability to excitotoxic brain injury is dependent upon developmental age. Fidia Res Fnd Sym Series 5:609-614

Marshall BE, Longnecker DE (1990): General anesthetics. In Goodman LS, Gilman A, Rall TW, Nies AS, Taylor P (eds), The Pharmacologic Basis of Therapeutics. New York, Pergamon, pp 285-310

Maura G, Giardi A, Raiteri M (1988): Release-regulating $D_{2}$ dopamine receptors are located on striatal glutamatergic nerve terminals. J Pharmacol Exp Ther 247:680-684

Maura G, Carbone R, Raiteri M (1989): Aspartate-releasing nerve terminals in rat striatum possess $D_{2}$ dopamine receptors mediating inhibition of release. J Pharmacol Exp Ther 251:1142-1146

Maura G, Barzizza A, Lottero P, Raiteri M (1990): The excitatory amino acid-releasing nerve terminals in rat striatum possess $\mathrm{D}_{2}$ dopamine receptors mediating inhibition of release. Neurochem Inter 16:53

Monnet FP, Debonnel G, Junien JL, De Montigny C (1990). $\mathrm{N}$-methyl-D-aspartate-induced neuronal activation is selectively modulated by sigma receptors. Eur J. Pharmacol 179:441-445

Monnet FP, Debonnel G, and De Montigny C (1992). In vivo electrophysiologic evidence for a selective modulation on N-methyl-D-aspartate-induced neuronal activation in rat $\mathrm{CA}_{3}$ dorsal hippocampus by sigma ligands. J Pharmacol Exp Ther 261:123-130

Monyer HR, Burnashev N, Laurie DJ, Sakmann B, Seeburg PH (1994): Developmental and regional expression in the 
rat brain and functional propertıes of four NMDA receptors. Neuron 12:529-540

Olney JW (1988): Endogenous excitotoxins and neuropathological disorders. In Lodge D (ed), Excitatory Amino Acids in Health and Disease. England, John Wiley \& Sons, pp 337-351

Olney JW (1989): Excitatory amino acids and neuropsychiatric disorders. Biol Psychiatry 26:505-525

Olney JW, Farber NB (1994): Efficacy of clozapine compared to other antipsychotics in preventing NMDA antagonist neurotoxicity. J Clin Psychiatry 55:9(supplement 8) 43-46

Olney JW, Farber NB (1995): Glutamate receptor dysfunction and schizophrenia. Arch Gen Psychiatry (in press)

Olney JW, Ikonomidou C, Mosinger Il., Frierdich C, (1989a) MK-801 prevents hypobaric-ishemic neuronal degener ation in infant rat brain. J Neurosci 9:1701-1704

Olney JW, Labruyere J, Price MT (1989b): Pathologic changes induced in cerebrocortical neurons by phencyclidine and related drugs. Science 244:1360-1362

Olney JW, Labruyere J, Wang G, Sesma MA, Wozniak DF Price MT (1991): NMDA antagonist neurotoxicity: Mechanism and Protection. Science 254:1515-1518

Olney JW, Sesma MA, Wozniak DF (1993): Glutamatergic cholinergic, and GABAergic systems in posterior cingulate cortex: Interactions and possible mechanism of limbic system disease. In Vogt BA. Gabriel M (eds), Neurobiology of Cingulate Cortes and Limbic Thalamus Boston, Birkhauser, pp 557 580

Pearce IA, Cambray-Deakin MA, Burgovne RD (1987): Glutamate acting on NMDA receptor stimulates neurite out growth from cerebellar granule cells. FEBS Lett 223 143-147

Price MT, Farber NB, Labruyere I. foster I, Olney JW (1994) Tracing the circuitry that mediates. NMDA antagonist neurotoxicity. Soc Neuroscl Abstr 20:1532

Puke MJC, Wiesenfeld-Hallin Z (1993): The differential effects of morphine and the $\alpha_{2}$-adrenoceptor agonists clonidine' and dexmedetomidine on the prevention and treatment of experimental neuropathic pain. Anesth Analg 77 104-109

Riviere PJM, Pascaud X. Junten 11. Purreca F (1990). Neu ropeptide $Y$ and $J O$ 1784, a elective sigma ligand, alter intestinal ion transport through a common, haloperidolsensitive site. Eur J Pharmacol 187:557-559

Ruwlands GC, Roberts PJ (1980): Activation of domapine receptors inhibits calcium-dependent glutamate release from cortico-striatal terminals in vitro. Eur J Pharmacol 62:241-247

Shwarcz R, Creese I, Coyle JT, Snyder SH (1978): Dopamine receptors localized on cerebral cortical afferents to rat corpus striatum. Nature 271:766-768

Sharp FR, Butman M, Koistinaho J, Aardalen K, Nakki R, Massa SM, Swanson R, Sagar SM (1994): Phencyclidine induction of hsp70 stress gene in injured pyramidal neurons is mediated via multiple receptors and voltage gated calcium channels. Neuroscience 62(4): 1079-1092

Shenton ME, Kikinis R, Jolesz FA, Pollak SD, LeMay M, Wible CG, Hokama H, Martin J, Metcalf D, Coleman M, McCarley RW (1992): Abnormalities of the left temporal lobe and thought disorder in schizophrenia: A quantitative magnetic resonance imaging study. $N$ Engl J Med 327:604-612

Tandon R, Greden JF, Silk KR (1988): Treatment of negative schizophrenic symptoms with trihexiphenidyl. J Clin Psychopharmacol 8:212-215

Iandon R, Greden JF (1989): Cholinergic hyperactivity and negative schizophrenic symptoms. Arch Gen Psychiatry 46:745-753

Tandon R, Shipley JE, Greden JF, Mann NA, Eisner WH, Goodson J (1991): Muscarinic cholinergic hyperactivity in schizophrenia. Relationship to positive and negative symptoms. Schizophr Res 4:23-30

Walker FA, Seig JA (1973): Phencyclidine an environmental teratogen. Mutat Res 21:348-349

Wells BG, Marken PA, Richman LA, Brown CS, Hamann G, Grimmig J (1989): Characterizing anticholinergic abuse in community mental health. J Clin Pharmacol 9:431-435

Wozniak DF, McEwen M, Sesma MA, Olney JW, Fix AS (1993): MK-801 induces extensive neuronal necrosis in posterior cingulate'retrosplenial cortices. Soc Neurosci Abstr 19:1770

Zeigler D, lynch SA, Muir J, Benjamin I, Max MB (1992): Transdermal clonidine versus placebo in painful diabetic neuropathy. Pain 48:403-408 